\title{
Review of Hemorrhoid Disease: Presentation and Management
}

\author{
Zhifei Sun, MD ${ }^{1}$ John Migaly, MD ${ }^{1}$ \\ ${ }^{1}$ Department of Surgery, Duke University, Durham, North Carolina \\ Clin Colon Rectal Surg 2016;29:22-29.
}

Address for correspondence Zhifei Sun, MD, Department of Surgery,
Duke University Medical Center, Box 3443, Durham, NC 27710 (e-mail: zhifei.sun@duke.edu).
Abstract Keywords
- hemorrhoids
- rectal bleeding
- thrombosis
- management

Symptomatic hemorrhoid disease is one of the most prevalent ailments associated with significant impact on quality of life. Management options for hemorrhoid disease are diverse, ranging from conservative measures to a variety of office and operating-room procedures. In this review, the authors will discuss the anatomy, pathophysiology, clinical presentation, and management of hemorrhoid disease.
Hemorrhoid disease is the fourth leading outpatient gastrointestinal diagnosis, accounting for $\sim 3.3$ million ambulatory care visits in the United States. ${ }^{1}$ Self-reported incidence of hemorrhoids in the United States is 10 million per year, corresponding to $4.4 \%$ of the population. Both genders report peak incidence from age 45 to 65 years. Notably, Caucasians are affected more frequently than African Americans, and higher socioeconomic status is associated with increased prevalence. ${ }^{2}$ Contributing factors for increased incidence of symptomatic hemorrhoids include conditions that elevate intra-abdominal pressure such as pregnancy and straining, or those that weaken supporting tissue.

Despite its prevalence and low morbidity, hemorrhoid disease has a high impact on quality of life, and can be managed with a multitude of surgical and nonsurgical treatments. In this review, we will discuss the anatomy, presentation, and management of symptomatic hemorrhoid disease.

\section{Anatomy and Pathophysiology}

Hemorrhoids are clusters of vascular tissues, smooth muscles, and connective tissues that lie along the anal canal in three columns-left lateral, right anterior, and right posterior positions. Because some do not contain muscular walls, these clusters may be considered sinusoids instead of arteries or veins (-Fig. 1). ${ }^{3}$ Hemorrhoids are present universally in healthy individuals as cushions surrounding the anastomoses between the superior rectal artery and the superior, middle, and inferior rectal veins. Nonetheless, the term "hemorrhoid" is commonly invoked to characterize the pathologic process of symptomatic hemorrhoid disease instead of the normal anatomic structure.

Classification of a hemorrhoid corresponds to its position relative to the dentate line. External hemorrhoids are located below the dentate line and develop from ectoderm embryonically. They are covered with anoderm, composed of squamous epithelium, and are innervated by somatic nerves supplying the perianal skin and thus producing pain. Vascular outflows of external hemorrhoids are via the inferior rectal veins into the pudendal vessels and then into the internal iliac veins. In contrast, internal hemorrhoids lie above the dentate line and are derived from endoderm. They are covered by columnar epithelium, innervated by visceral nerve fibers and thus cannot cause pain. Vascular outflows of internal hemorrhoids include the middle and superior rectal veins, which subsequently drain into the internal iliac vessels.

While no taxonomy of external hemorrhoids is used clinically, internal hemorrhoids are further stratified by the severity of prolapse. First-degree internal hemorrhoids do not prolapse out of the canal but are characterized by prominent vascularity. Second-degree hemorrhoids prolapse outside of the canal during bowel movements or straining, but reduce spontaneously. Third-degree hemorrhoids prolapse out of the canal and require manual reduction. Fourth-degree hemorrhoids are irreducible even with manipulation. ${ }^{4}$

The exact pathophysiology of symptomatic hemorrhoid disease is poorly understood. Previous theories of hemorrhoids as anorectal varices are now obsolete-as shown by Goenka et al, patients with portal hypertension and varices do not have an
Issue Theme Approaches to Anorectal Disease; Guest Editor: Sean J. Langenfeld, MD, FACS
Copyright @ 2016 by Thieme Medical Publishers, Inc., 333 Seventh Avenue, New York, NY 10001, USA. Tel: +1(212) 584-4662.
DOI http://dx.doi.org/ 10.1055/s-0035-1568144. ISSN 1531-0043. 


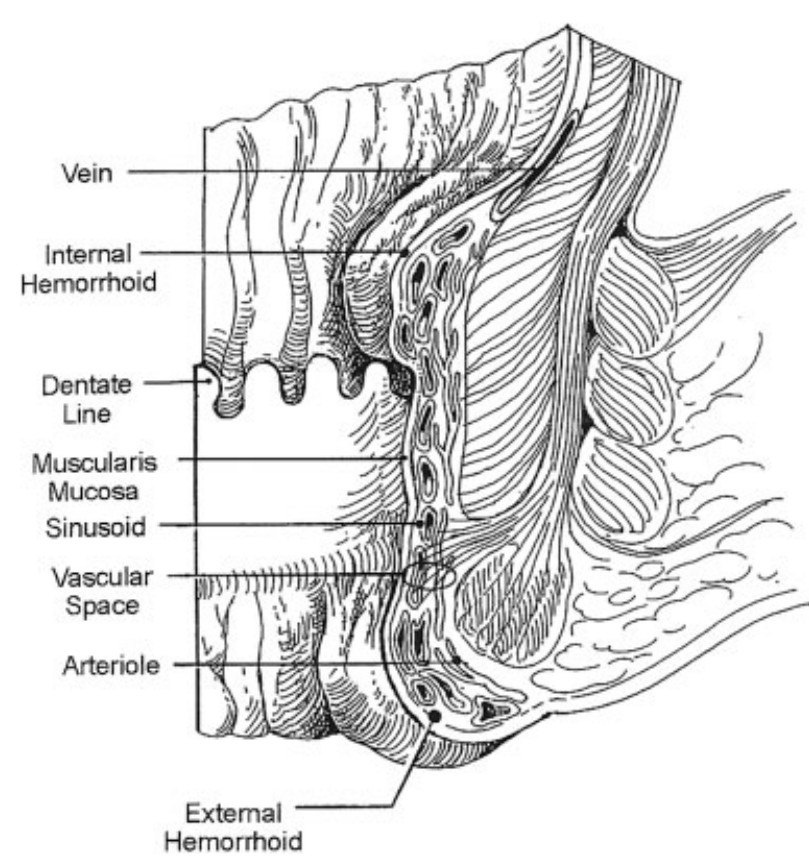

Fig. 1 Anatomy of the anal canal and vasculature of hemorrhoids. (Reprinted with permission from Cintron J, Abcarian H. Benign anorectal: hemorrhoids. In: The ASCRS Textbook of Colon and Rectal Surgery. New York, NY: Springer-Verlag, Inc; 2007:156-77; with kind reprint permission of Springer Science + Business Media.)

increased incidence of hemorrhoids. ${ }^{5}$ Currently, the theory of sliding anal canal lining, which proposes that hemorrhoids occur when the supporting tissues of the anal cushions deteriorate, is more widely accepted. Advancing age and activities such as strenuous lifting, straining with defecation, and prolonged sitting are thought to contribute to this process. Hemorrhoids are therefore the pathological term to describe the abnormal downward displacement of the anal cushions causing venous dilatation. ${ }^{6}$ On histopathological examination, changes seen in the anal cushions include abnormal venous dilatation, vascular thrombosis, degenerative process in the collagen fibers and fibroelastic tissues, and distortion and rupture of the anal subepithelial muscle. In severe cases, a prominent inflammatory reaction involving the vascular wall and surrounding connective tissue has been associated with mucosal ulceration, ischemia, and thrombosis. ${ }^{7}$

\section{Symptoms and Presentation}

A total of $40 \%$ of individuals with hemorrhoids are asymptomatic. ${ }^{8}$ For symptomatic hemorrhoids, there is great variance in the constellation of symptoms. In addition, many other anorectal pathologies such as anal fissure, fistula, pruritus, condyloma, and even anal cancer are often labeled as "hemorrhoids" by the layperson.

For internal hemorrhoids, bleeding is the most commonly reported symptom. The occurrence of bleeding is usually associated with defecation and almost always painless. The blood is bright red and coats the stool at the end of defection. Blood can be found on the toilet paper, dripping into the bowl, or even dramatically spraying across the toilet bowl. Another frequent symptom is the sensation of tissue prolapse. Prolapsed internal hemorrhoids may accompany mild fecal incontinence, mucus discharge, sensation of perianal fullness, and irritation of perianal skin. Pain is significantly less common with internal hemorrhoids than with external hemorrhoids, but can occur in the setting of prolapsed, strangulated internal hemorrhoids that develop gangrenous changes due to the associated ischemia.

In contrast, external hemorrhoids are more likely to be associated with pain, due to activation of perianal innervations associated with thrombosis. Patients typically describe a painful perianal mass that is tender to palpation. This painful mass may be initially increasing in size and severity over time. Bleeding can also occur if ulceration develops from necrosis of the thrombosed hemorrhoid, and this blood tends to be darker and more clotted than the bleeding from internal disease. Painless external skin tags often result from previous edematous or thrombosed external hemorrhoids.

\section{Physical Examination}

Rectal pain and bleeding should never be blindly attributed to hemorrhoids. A thorough history and physical examination is required to help identify any possible alternative diagnosis, and the possibility of a more insidious cause of rectal bleeding should always be considered. In the colorectal surgeon's office, a detailed anorectal examination is crucial to diagnosis. Patients may be examined in a prone-jackknife or left lateral position. External inspection will reveal any thrombosed external hemorrhoid, which often appears as a firm, purplish nodule that is tender to palpation. Thrombosed hemorrhoids may also have ulcerations with bloody drainage. Skin tags maybe signs not only of prior hemorrhoids but also of fissure disease. Digital examination will exclude distal rectal mass and anorectal abscess or fistula. Evaluation of sphincter integrity during the digital examination is important to establish baseline function, and is especially important in patients who report incontinence as any future surgical intervention may further worsen function. Lastly, anoscopy and rigid or flexible proctosigmoidoscopy should be performed routinely to identify internal hemorrhoids or fissures, and to rule out distal rectal masses. Internal hemorrhoids can be reliably identified in the three above-mentioned columns, and described based on grade and degree of inflammation.

If uncertainty remains after office examination, a total colonoscopy is often appropriate to rule out a proximal source of bleeding. Certainly, any patient over the age of 50 years without an up-to-date colonoscopy requires this to be performed. For younger patients, the decision for colonoscopy must be based on risk factors, clinical suspicion, and response to initial therapy.

\section{Management of Hemorrhoid Disease}

The natural history of most cases of hemorrhoid disease is selflimited. For symptomatic hemorrhoid disease that presents to the clinic or emergency room, treatments range from nonoperative medical interventions and office-based procedures to 
surgery. One general guiding principle is that the least-invasive approaches should be considered first, except in cases of acute thrombosis. Specific choices of treatments depend on patients' age, severity of symptoms, and comorbidities. A summary of management strategies is shown in - Table $\mathbf{1}$.

\section{Conservative Medical Treatments}

Lifestyle and dietary modification are the mainstays of conservative medical treatment of hemorrhoid disease. Specifically, lifestyle modifications should include increasing oral fluid intake, reducing fat consumptions, avoiding straining, and regular exercise. Diet recommendations should include increasing fiber intake, which decreases the shearing action of passing hard stool. In a meta-analysis of seven randomized trials comparing fiber to nonfiber controls, fiber supplementation (7-20 g/d) reduced risk of persisting symptoms and bleeding by $50 \%$. However, fiber intake did not improve symptoms of prolapse, pain, and itching. ${ }^{9}$

For symptomatic control, topical treatments containing various local anesthetics, corticosteroids, or anti-inflammatory drugs are available. Notable topical drugs include $0.2 \%$ glyceryl trinitrate, which has been studied to relieve grade I or II hemorrhoids with high resting anal canal pressures, but is associated with headaches in $43 \%$ of patients. ${ }^{10}$ Patients also commonly self-medicate with Preparation-H (Pfizer Incorporated, Kings Mountain, NC), a formulation of phenylephrine, petroleum, mineral oil, and shark liver oil (vasoconstrictor and protectants), which provides temporary relief in acute symptoms of hemorrhoids such as bleeding and pain on defecation. ${ }^{11}$ Topic corticosteroids in cream or ointment formulations are commonly prescribed, but their efficacy remains unproven.

Except in the case of thrombosis, both internal and external hemorrhoids respond readily to conservative medical therapy. However, when medical interventions fail to resolve symptoms or if the extent of hemorrhoid disease is severe, there are various options for invasive procedures available to the colorectal surgeon.

\section{Nonsurgical Office-based Procedures}

For internal hemorrhoids, rubber band ligation, sclerotherapy, and infrared coagulation are the most common procedures but there is no consensus on optimal treatment. Overall, the goals of each procedure are to decrease vascularity, reduce redundant tissue, and increase hemorrhoidal rectal wall fixation to minimize prolapse.

\section{Rubber Band Ligation}

Rubber band ligation is the most commonly performed procedure in the office and is indicated for grade II and III internal hemorrhoids. ${ }^{12}$ Contraindications include symptomatic external disease and patients with coagulopathies or on chronic anticoagulation (due to risk of delayed hemorrhage). There is also an increased risk of sepsis in immunocompromised patients. ${ }^{13}$ Performing rubber band ligation does not require any local anesthetic. Patients are placed in jackknife or left lateral position and the procedure is performed through an anoscope. Several platforms are available, but the two most prevalent ligating devices are the McGivney forceps ligator and the suction ligator. Small rubber band rings are deployed tightly around the base of the internal hemorrhoids. They should be placed at least half a centimeter above dentate line to avoid placement into somatically innervated tissue (-Fig. 2). Patients should be asked about presence of pain prior to release of rubber bands. While it is safe to ligate more than one column during a single visit, some experts recommend starting with a single column during the first visit to accurately assess the patient's tolerance of the technique. ${ }^{11}$

Rubber band ligation works by causing hemorrhoid tissue necrosis and its fixation to the rectal mucosa. As the tissues become ischemic, necrosis develops in the following 3 to 5 days, and an ulcerated tissue bed is formed. Complete healing occurs several weeks later. Complications are very uncommon, but those may occur include pain, urinary retention, delayed bleeding, and very rarely perineal sepsis.

Table 1 Summary of management options for hemorrhoids

\begin{tabular}{|l|l|l|l|l|l|}
\hline Treatment & Grade I & Grade II & Grade III & Grade IV & $\begin{array}{l}\text { Acute thrombosis and } \\
\text { strangulation }\end{array}$ \\
\hline Dietary and lifestyle modification & $\mathrm{X}$ & $\mathrm{X}$ & $\mathrm{X}$ & $\mathrm{X}$ & $\mathrm{X}$ (after acute event) \\
\hline Office procedures & & & & & \\
\hline Rubber band ligation & $\mathrm{X}$ & $\mathrm{X}$ & $\mathrm{X}$ & & \\
\hline Sclerotherapy & $\mathrm{X}$ & $\mathrm{X}$ & & & \\
\hline Infrared coagulation & $\mathrm{X}$ & $\mathrm{X}$ & & & \\
\hline Operating-room procedures & & & & & \\
\hline Hemorrhoidectomy & & & $\mathrm{X}$ & $\mathrm{X}$ & $\mathrm{X}$ (emergent) \\
\hline Stapled hemorrhoidopexy & & & $\mathrm{X}$ & $\mathrm{X}$ & \\
\hline Doppler-guided hemorrhoid artery ligation & & $\mathrm{X}$ & $\mathrm{X}$ & & \\
\hline
\end{tabular}

Source: Adapted and modified with permission from Cintron J, Abcarian H. Benign anorectal: hemorrhoids. In: The ASCRS Textbook of Colon and Rectal Surgery. New York, NY: Springer-Verlag, Inc; 2007:156-77; with kind reprint permission of Springer Science + Business Media. 


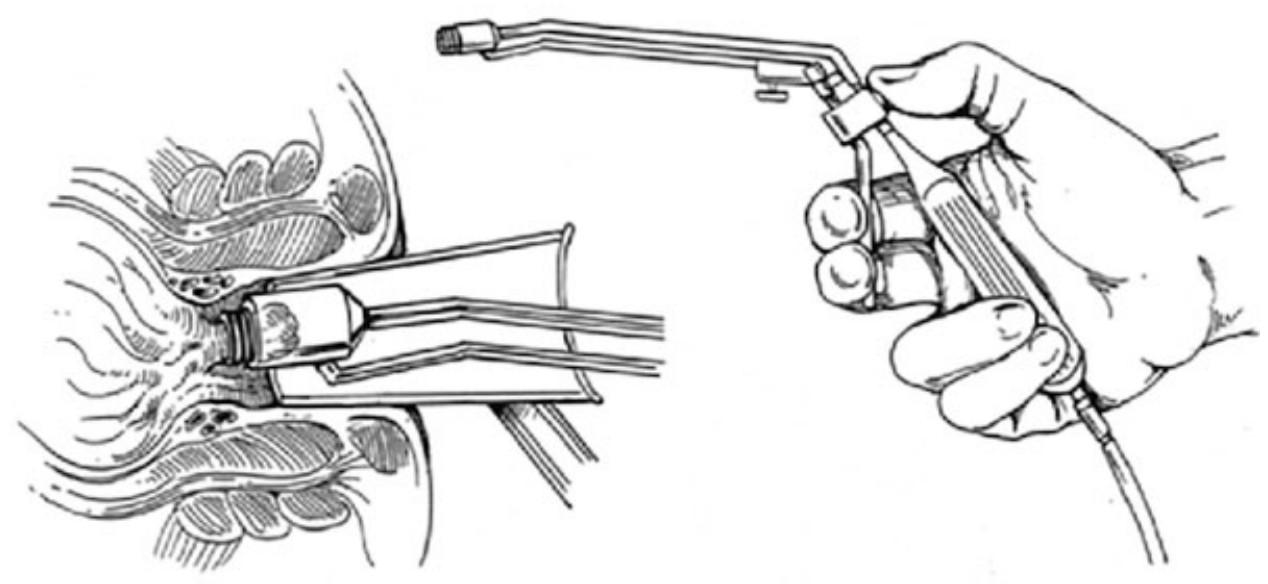

Fig. 2 Banding of an internal hemorrhoid through an anoscope using a McGown suction-ligator. (Adapted with permission from Cintron J, Abcarian H. Benign anorectal: hemorrhoids. In: The ASCRS Textbook of Colon and Rectal Surgery. New York, NY: Springer-Verlag, Inc; 2007:15677; with kind reprint permission of Springer Science + Business Media.)

In a large review of 805 patients from a single practice that performed 2,114 rubber band ligations, hemorrhoid disease requiring the placement of four or more bands was associated with a trend in higher failure rates and greater need for subsequent hemorrhoidectomy. Complications observed in this patient cohort included bleeding (2.8\%), thrombosed external hemorrhoids (1.5\%), and bacteremia (0.09\%). Higher bleeding rates were encountered with the use of aspirin, nonsteroidal anti-inflammatory drugs, and warfarin. ${ }^{14}$ Time to recurrence was less with subsequent treatment courses and treatment of recurrent symptoms with rubber band ligation resulted in success rates of 73,61 , and $65 \%$ for the first, second, and third recurrences, respectively. Cumulatively, a success rate of $80 \%$ is observed with rubber band ligation. ${ }^{12}$ Overall, banding is a safe, quick, and effective procedure for internal hemorrhoids.

\section{Sclerotherapy}

Sclerotherapy is indicated for patients with grade I and II internal hemorrhoids and may be a good option for patients on anticoagulants. Like rubber band ligation, sclerotherapy does not require local anesthesia. Performed through an anoscope, internal hemorrhoids are located and injected with a sclerosant material-typically a solution including phenol in vegetable oil-into the submucosa. The sclerosant subsequently causes fibrosis, fixation to the anal canal, and eventual obliteration of the redundant hemorrhoidal tissue. Complications of sclerotherapy include minor discomfort or bleeding. However, rectal fistulas or perforation can very rarely occur due to misplaced injections. ${ }^{15}$

\section{Infrared Coagulation}

Infrared coagulation refers to direct application of infrared light waves to the hemorrhoidal tissues and can be used for grade I and II internal hemorrhoids. To perform this procedure, the tip of the infrared coagulation applicator is usually applied to the base of the internal hemorrhoid for 2 seconds, with three to five treatments per hemorrhoid. By converting infrared light waves to heat, the applicator causes necrosis of the hemorrhoid, visualized as a white, blanched mucosa. Over time, the affected mucosa scars, leading to retraction of the prolapsed hemorrhoid mucosa. This procedure is very safe with only minor pain and bleeding reported.

As a comparison of the various office-based procedures, MacRae and McLeod conducted a meta-analysis of 18 trials and concluded that rubber band ligation was better than sclerotherapy in response to treatment for grade I and III hemorrhoids, with no differences in the complication rate. ${ }^{16}$ The authors also noted that patients treated with sclerotherapy or infrared coagulation were more likely to require additional subsequent procedure or therapies in comparison to those treated with rubber band ligation. Finally, although pain was greater after rubber band ligation, recurrent symptoms were less common.

\section{Surgical Procedures}

Continued symptoms despite conservative or minimally invasive measures usually require surgical intervention. In addition, surgery is the initial treatment of choice in patients with symptomatic grade IV hemorrhoids or those who have strangulated internal hemorrhoids. It may also be required for symptomatic grade III hemorrhoids and in patients who present with thrombosed hemorrhoids.

For patients who present with thrombosed external hemorrhoids, surgical evaluation and intervention within 72 hours of thrombosis may result in significant relief, as pain and edema peak at 48 hours. ${ }^{17}$ However, after 48 to 72 hours, organization of the thrombus and amelioration of symptoms generally obviates the need for surgical evacuation, which is consistent with the natural history of hemorrhoidal thrombosis. After the initial 72-hour window, the pain typically plateaus and slowly improves, at which point the pain from hemorrhoid excision would exceed the pain from the thrombosis itself.

For those patients requiring intervention, excision of the thrombosed hemorrhoid can be performed in the office or emergency-room setting and rarely requires the operating room. The thrombosed hemorrhoid should be injected with a 
local anesthetic, followed by an elliptical incision and excision of the entire thrombosed hemorrhoid. Simple incision and drainage is insufficient, and leads to increased rates of symptom recurrence due to inadequate clot evacuation. Postprocedure management includes analgesics and sitz baths. A retrospective review of 231 patients who received excision versus conservative management of thrombosed hemorrhoid showed that time to symptom resolution averaged 24 days in the conservative group versus 3.9 days in the surgical group. ${ }^{18}$

In the nonemergent setting, popular procedures performed in the operating room include hemorrhoidectomy, stapled hemorrhoidopexy, and Doppler-guided hemorrhoidal artery ligation.

\section{Hemorrhoidectomy}

There are two major types of hemorrhoidectomy: Ferguson, or closed hemorrhoidectomy and the Milligan-Morgan, or open hemorrhoidectomy. The open hemorrhoidectomy is often the preferred approach to surgically treat severe acute gangrenous hemorrhoids where tissue edema and necrosis preclude closure of the mucosa (-Fig. 3). ${ }^{19}$ Preoperatively, full mechanical bowel prep is not indicated. Additionally, there is no benefit to perioperative antibiotic administration. ${ }^{20}$
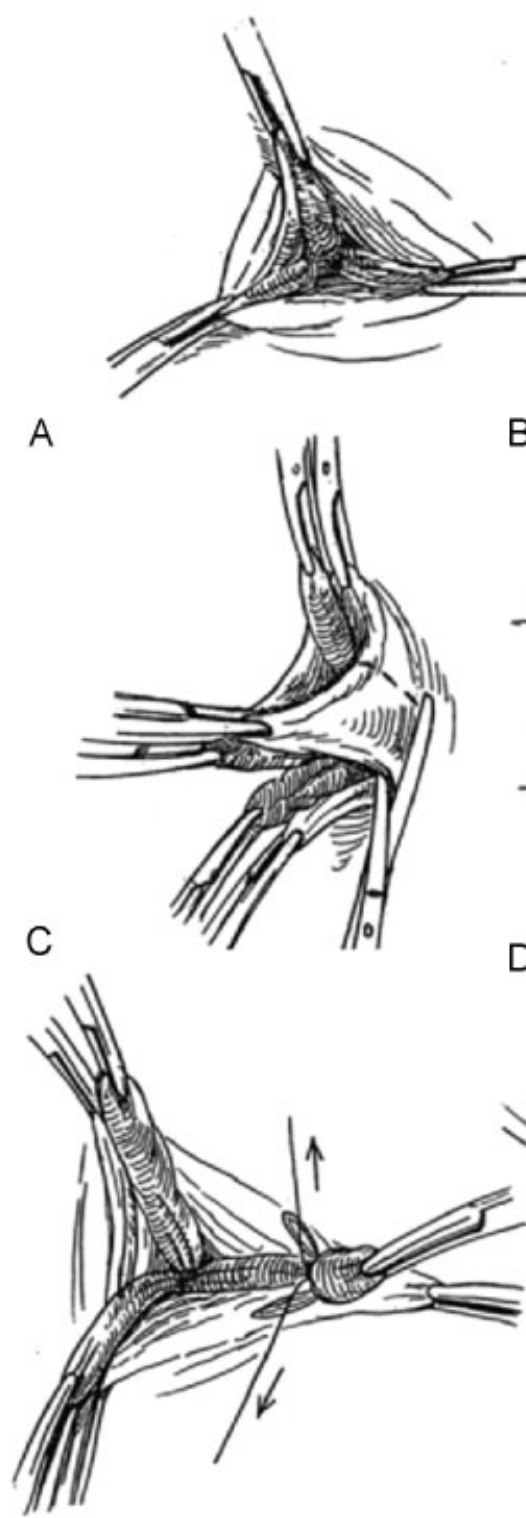

E

$\mathrm{F}$
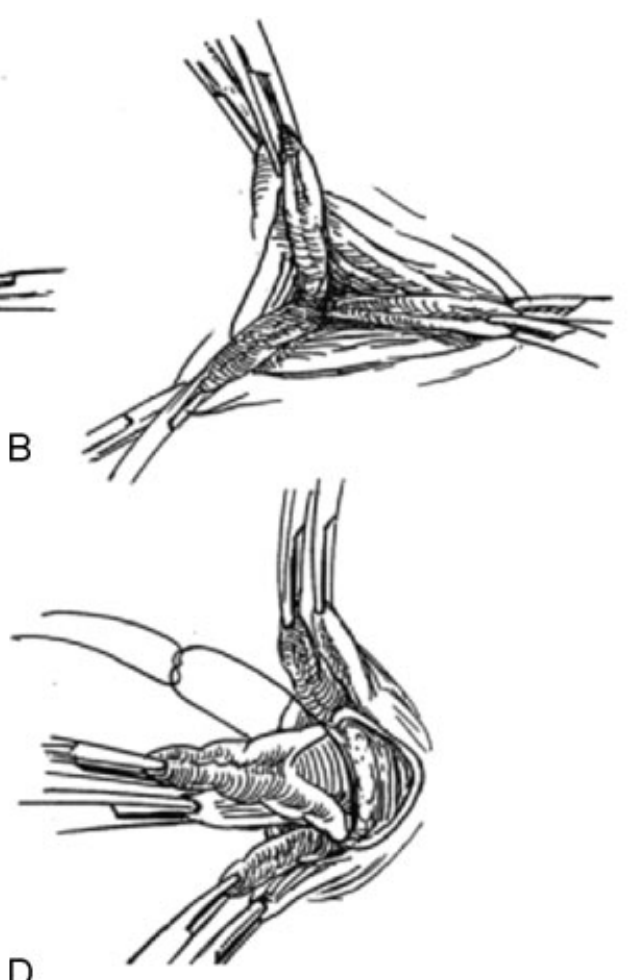

$\mathrm{D}$

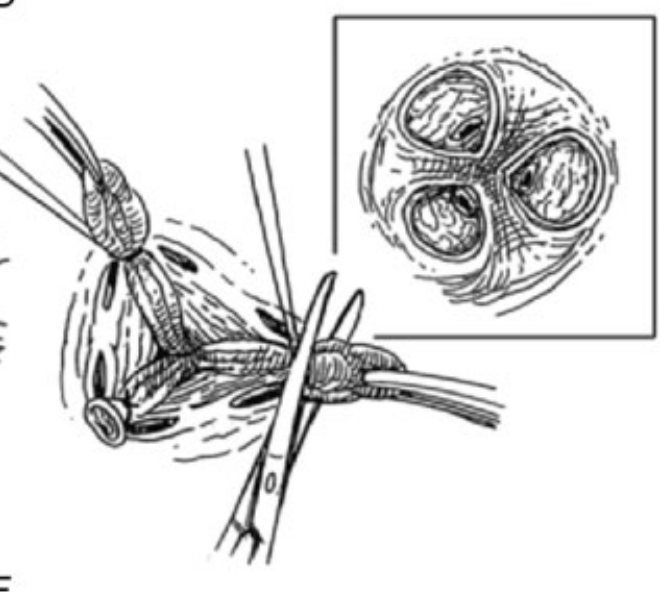

Fig. 3 Open (Milligan-Morgan) hemorrhoidectomy. Panel A: external hemorrhoid is grasped. Panel B: internal hemorrhoid is grasped. Panel C: external skin and hemorrhoids excised. Panel D: tie placed around the hemorrhoid vascular bundle. Panel E: ligation of the vascular bundle. Panel F: excision of the hemorrhoid tissue distal to the tie. (Reprinted with permission from Cintron J, Abcarian H. Benign anorectal: hemorrhoids. In: The ASCRS Textbook of Colon and Rectal Surgery. New York, NY: Springer-Verlag, Inc; 2007:156-77; with kind reprint permission of Springer Science + Business Media.). 
An excisional hemorrhoidectomy typically begins with the injection of a local anesthetic, often containing epinephrine to help with bleeding and swelling. After a Hill-Ferguson retractor is placed into the anal canal for exposure, the junction of the internal and external component of the hemorrhoid is grasped and serves as a handle to retract the hemorrhoid away from the sphincter muscles. An elliptical incision is made, and the hemorrhoid tissue is carefully dissected away from the superficial internal and external sphincter muscles to the main vascular pedicle in the anal canal, carefully avoiding any injury to the anal sphincters. The base of the pedicle is ligated and the hemorrhoid is excised. Devices using advanced energy, such as ultrasonic shears or a bipolar vessel sealant, can be used to perform this procedure with similar efficacy. ${ }^{21}$

Operative hemorrhoidectomy is a relatively morbid procedure compared with other less-invasive options. Due to the extent of dissection and the presence of incisions below the dentate line, postoperative pain can be severe, and may delay return to normal activities for several weeks. Pain can usually be managed with oral analgesics, avoidance of constipation, and sitz baths. Bleeding may occur in 1 to $2 \%$ of patients after 1 week from surgery as a result of eschar separation and is usually self-limited. ${ }^{22}$ Infection is uncommon after hemorrhoid surgery with submucosal abscesses occurring in less than $1 \%$ of cases and severe fasciitis or necrotizing infections are rare. ${ }^{22}$ Urinary retention has been reported to be as high as $34 \%$ after hemorrhoidectomy, which is attributed to pelvic floor spasm, narcotic use, and excess intravenous fluids. ${ }^{23}$ Treatment for urinary retention after hemorrhoidectomy is temporary Foley catheter insertion with self-resolution in majority of cases. Injury to the sphincter resulting in fecal incontinence occurs in 2 to $10 \%$ of cases and can have significant impact on quality of life. ${ }^{24}$ Lastly, anal stenosis is a late complication that can result from excessive tissue resection or aggressive suturing. Stenosis is more common with multiple excised quadrants; it is often difficult to treat and should be diligently avoided by assuring adequate mucosal bridges between the excised hemorrhoids.

Despite its relative higher morbidity, surgical hemorrhoidectomy is more effective than band ligation for preventing recurrent symptoms. ${ }^{16}$ In a randomized trial among elective cases, there were no differences in open versus closed hemorrhoidectomy. ${ }^{25}$ Patients with grade III and IV hemorrhoids benefit the most from surgical hemorrhoidectomy.

\section{Stapled Hemorrhoidopexy}

An alternative to operative hemorrhoidectomy is stapled hemorrhoidopexy, in which a stapling device is used to resect and fixate the internal hemorrhoid tissues to the rectal wall. Since the staple line is above the dentate line, patients typically experience less pain than those who undergo hemorrhoidectomy. To perform this procedure, a circular stapler is introduced into the anus and prolapsing tissue is brought into the stapler. The most critical component of stapled hemorrhoidopexy is the placement of a circumferential, purse-string, nonabsorbable suture in the submucosa far enough away to avoid any sphincter muscle involvement-usually at $\sim 4 \mathrm{~cm}$ from the dentate line.
Additionally, before engaging the stapler, an examination of the posterior vaginal wall should be conducted. Finally, the staple line should be evaluated for any bleeding that would require additional suture ligation.

Complications from stapled hemorrhoidopexy include bleeding from the staple line, incontinence for injury of the sphincter muscles, and stenosis from incorporation of excess rectal tissue. Moreover, there is a risk of recto-vaginal fistula in women due to incorporation of vaginal tissue into the purse-string.

Three systematic reviews concluded that stapled hemorrhoidopexy was less effective than conventional hemorrhoidectomy. ${ }^{26-28}$ Stapled hemorrhoidopexy was associated with a higher long-term risk of hemorrhoid recurrence. Due to need for additional operations, the incidence of prolapse and tenesmus was also higher after stapled hemorrhoidopexy as compared with hemorrhoidectomy. Conversely, the stapled approach was associated with significantly less pain, shorter operative time, and shorter time to resumption of normal activity. In a 2010 European multicenter randomized trial of stapled hemorrhoidopexy versus hemorrhoidectomy, both options were shown to be equally effective in preventing recurrence after 1 year. Patients undergoing hemorrhoidectomy were more likely to have symptomatic relief from the hemorrhoids ( 69 vs. $44 \%$ ), but had significantly greater postoperative pain. ${ }^{29}$

Overall, stapled hemorrhoidopexy remains a viable alternative to hemorrhoidectomy, and is especially attractive for patients without much external disease. However, while the published complication rates are low, they can be quite severe, and the surgeon must have appropriate training and proceed with great caution, when performing this procedure.

\section{Doppler-guided Hemorrhoidal Artery Ligation}

First described by Morinaga et al in 1995, this technique involves use of Doppler ultrasound to identify and ligate the hemorrhoidal arteries. ${ }^{30}$ This is also referred to as transanal hemorrhoidal dearterialization (THD). Different platforms with different associated nomenclatures exist for this technique, but the principles include the use of a Doppler probe to identify the six main feeding arteries within the anal canal, ligation of these arteries with absorbable suture and a specialized anoscope, and then plication of redundant hemorrhoidal mucosa. The plication is often referred to as recto-anal-repair, mucopexy, or hemorrhoidopexy. Proposed benefits of this procedure are similar to stapled hemorrhoidopexy, with less associated pain due to the suturing being above the dentate line.

Early results of Doppler-guided hemorrhoidal artery ligation (DGHAL)/THD were promising, with lower pain scores than hemorrhoidectomy, and relief of bleeding and tissue prolapse in over $90 \%$ of patients. ${ }^{31}$ Since then, several randomized clinical trials have been performed with mixed results. ${ }^{32-34}$ Currently, DGHAL/THD remains a viable approach to multicolumn internal hemorrhoids. However, the short-term benefits regarding postoperative pain have recently not been as remarkable as in the earlier studies. 


\section{Special Considerations}

\section{Crohn Disease}

Hemorrhoids should be distinguished from hypertrophic skin tags that are associated with Crohn disease. Skin tags in Crohn disease are often tender and associated with ulceration of the anal canal. For patients with Crohn disease and active anorectal inflammation, treatment of hemorrhoids should be kept as conservative as possible, with every attempt made to avoid surgery, as these patients can have significant issues with wound healing after hemorrhoidectomy, and surgery may actually exacerbate their disease and worsen symptoms. Hemorrhoidectomy can be performed in a highly selective basis when disease is quiescent, but it is generally discouraged. ${ }^{35}$

\section{Immunosuppression}

Immunosuppressed patients such as those with acquired immunodeficiency syndrome (AIDS) or those on chronic immunosuppressive medications are at greater risk of sepsis and poor wound healing. ${ }^{36-38}$ Conservative treatments should be exhausted before performing any invasive procedures; however, less-invasive approaches can be undertaken. In a small series of 22 AIDS patients that underwent sclerotherapy injection of their hemorrhoids, all demonstrated improvement after 6 weeks. Four patients with 4-year follow-up showed improvement lasting 18 months but subsequently required repeat injections for recurrence symptoms. ${ }^{37}$

\section{Cirrhosis and Portal Hypertension}

Contrary to previous teachings, the incidence of hemorrhoid disease in patients with portal hypertension is not different from the general population. ${ }^{39}$ Rectal varices, the result of portosystemic communication via the hemorrhoid veins, occur commonly in patients with portal hypertension. However, bleeding from rectal varices is rare, accounting for $<1 \%$ of massive bleeding in portal hypertension. When it does occur, it should typically be treated with portal decompression. ${ }^{40}$

\section{Conclusion}

Hemorrhoid disease is a common but complex disease. Patients who present with signs and symptoms of hemorrhoids should be carefully evaluated to exclude other masquerading entities. There are a multitude of options for the management of hemorrhoid disease and specific treatment choice should be based on individual patient and clinical factors.

\section{Conflict of Interest}

None.

Source of Funding

None.

\section{References}

1 Everhart JE, Ruhl CE. Burden of digestive diseases in the United States part I: overall and upper gastrointestinal diseases. Gastroenterology 2009;136(2):376-386

2 Johanson JF, Sonnenberg A. The prevalence of hemorrhoids and chronic constipation. An epidemiologic study. Gastroenterology 1990;98(2):380-386

3 Shafik A. Surgical anatomy of hemorrhoids. Surgical Treatment of Hemorrhoids. London: Springer; 2009:7-13

4 Banov L Jr, Knoepp LF Jr, Erdman LH, Alia RT. Management of hemorrhoidal disease. J S C Med Assoc 1985;81(7):398-401

5 Goenka MK, Kochhar R, Nagi B, Mehta SK. Rectosigmoid varices and other mucosal changes in patients with portal hypertension. Am J Gastroenterol 1991;86(9):1185-1189

6 Thomson WH. The nature of haemorrhoids. Br J Surg 1975;62(7): 542-552

7 Morgado PJ, Suárez JA, Gómez LG, Morgado PJ Jr. Histoclinical basis for a new classification of hemorrhoidal disease. Dis Colon Rectum 1988;31(6):474-480

8 Riss S, Weiser FA, Schwameis K, et al. The prevalence of hemorrhoids in adults. Int J Colorectal Dis 2012;27(2):215-220

9 Alonso-Coello P, Mills E, Heels-Ansdell D, et al. Fiber for the treatment of hemorrhoids complications: a systematic review and meta-analysis. Am J Gastroenterol 2006;101(1):181-188

10 Tjandra JJ, Tan JJ, Lim JF, Murray-Green C, Kennedy ML, Lubowski DZ. Rectogesic (glyceryl trinitrate $0.2 \%$ ) ointment relieves symptoms of haemorrhoids associated with high resting anal canal pressures. Colorectal Dis 2007;9(5):457-463

11 Sneider EB, Maykel JA. Diagnosis and management of symptomatic hemorrhoids. Surg Clin North Am 2010;90(1):17-32

12 Iyer VS, Shrier I, Gordon PH. Long-term outcome of rubber band ligation for symptomatic primary and recurrent internal hemorrhoids. Dis Colon Rectum 2004;47(8):1364-1370

13 Buchmann P, Seefeld U. Rubber band ligation for piles can be disastrous in HIV-positive patients. Int J Colorectal Dis 1989;4(1): 57-58

14 Nelson RS, Ewing BM, Ternent C, Shashidharan M, Blatchford GJ, Thorson AG. Risk of late bleeding following hemorrhoidal banding in patients on antithrombotic prophylaxis. Am J Surg 2008;196(6): 994-999, discussion 999

15 Barwell J, Watkins RM, Lloyd-Davies E, Wilkins DC. Life-threatening retroperitoneal sepsis after hemorrhoid injection sclerotherapy: report of a case. Dis Colon Rectum 1999;42(3):421-423

16 MacRae HM, McLeod RS. Comparison of hemorrhoidal treatment modalities. A meta-analysis. Dis Colon Rectum 1995;38(7): 687-694

17 Aigner F, Gruber H, Conrad F, et al. Revised morphology and hemodynamics of the anorectal vascular plexus: impact on the course of hemorrhoidal disease. Int J Colorectal Dis 2009;24(1): 105-113

18 Greenspon J, Williams SB, Young HA, Orkin BA. Thrombosed external hemorrhoids: outcome after conservative or surgical management. Dis Colon Rectum 2004;47(9):1493-1498

19 Pattana-arun J, Wesarachawit W, Tantiphlachiva K, Atithansakul P, Sahakitrungruang C, Rojanasakul A. A comparison of early postoperative results between urgent closed hemorrhoidectomy for prolapsed thrombosed hemorrhoids and elective closed hemorrhoidectomy. J Med Assoc Thai 2009;92(12): $1610-1615$

20 Wesarachawit W, Pattana-arun J. Antibiotics and early post operative complications of closed hemorrhoidectomy: a retrospective matched pair study. J Med Assoc Thai 2007;90(9): 1828-1832

21 Nienhuijs S, de Hingh I. Conventional versus LigaSure hemorrhoidectomy for patients with symptomatic Hemorrhoids. Cochrane Database Syst Rev 2009;(1):CD006761 
22 Bleday R, Pena JP, Rothenberger DA, Goldberg SM, Buls JG. Symptomatic hemorrhoids: current incidence and complications of operative therapy. Dis Colon Rectum 1992;35(5):477-481

23 Hoff SD, Bailey HR, Butts DR, et al. Ambulatory surgical hemorrhoidectomy-a solution to postoperative urinary retention? Dis Colon Rectum 1994;37(12):1242-1244

24 Gravié JF, Lehur PA, Huten N, et al. Stapled hemorrhoidopexy versus Milligan-Morgan hemorrhoidectomy: a prospective, randomized, multicenter trial with 2-year postoperative follow up. Ann Surg 2005;242(1):29-35

25 Reis Neto JA, Quilici FA, Cordeiro F, Reis Júnior JA. Open versus semiopen hemorrhoidectomy: a random trial. Int Surg 1992;77(2):84-90

26 Giordano P, Gravante G, Sorge R, Ovens L, Nastro P. Long-term outcomes of stapled hemorrhoidopexy vs conventional hemorrhoidectomy: a meta-analysis of randomized controlled trials. Arch Surg 2009;144(3):266-272

27 Jayaraman S, Colquhoun PH, Malthaner RA. Stapled versus conventional surgery for hemorrhoids. Cochrane Database Syst Rev 2006;(4):CD005393

28 Nisar PJ, Acheson AG, Neal KR, Scholefield JH. Stapled hemorrhoidopexy compared with conventional hemorrhoidectomy: systematic review of randomized, controlled trials. Dis Colon Rectum 2004;47(11):1837-1845

29 Nyström PO, Qvist N, Raahave D, Lindsey I, Mortensen N; Stapled or Open Pile Procedure (STOPP) trial study group. Randomized clinical trial of symptom control after stapled anopexy or diathermy excision for haemorrhoid prolapse. Br J Surg 2010;97(2):167-176

30 Morinaga K, Hasuda K, Ikeda T. A novel therapy for internal hemorrhoids: ligation of the hemorrhoidal artery with a newly devised instrument (Moricorn) in conjunction with a Doppler flowmeter. Am J Gastroenterol 1995;90(4):610-613

31 Giordano P, Overton J, Madeddu F, Zaman S, Gravante G. Transanal hemorrhoidal dearterialization: a systematic review. Dis Colon Rectum 2009;52(9):1665-1671
32 De Nardi P, Capretti G, Corsaro A, Staudacher C. A prospective, randomized trial comparing the short- and long-term results of Doppler-guided transanal hemorrhoid dearterialization with mucopexy versus excision hemorrhoidectomy for grade III hemorrhoids. Dis Colon Rectum 2014;57(3):348-353

33 Denoya PI, Fakhoury M, Chang K, Fakhoury J, Bergamaschi R. Dearterialization with mucopexy versus haemorrhoidectomy for grade III or IV haemorrhoids: short-term results of a double-blind randomized controlled trial. Colorectal Dis 2013;15(10): 1281-1288

34 Elmér SE, Nygren JO, Lenander CE. A randomized trial of transanal hemorrhoidal dearterialization with anopexy compared with open hemorrhoidectomy in the treatment of hemorrhoids. Dis Colon Rectum 2013;56(4):484-490

35 Wolkomir AF, Luchtefeld MA. Surgery for symptomatic hemorrhoids and anal fissures in Crohn's disease. Dis Colon Rectum 1993;36(6):545-547

36 Morandi E, Merlini D, Salvaggio A, Foschi D, Trabucchi E. Prospective study of healing time after hemorrhoidectomy: influence of HIV infection, acquired immunodeficiency syndrome, and anal wound infection. Dis Colon Rectum 1999; 42(9):1140-1144

37 Scaglia M, Delaini GG, Destefano I, Hultén L. Injection treatment of hemorrhoids in patients with acquired immunodeficiency syndrome. Dis Colon Rectum 2001;44(3):401-404

38 Wexner SD, Smithy WB, Milsom JW, Dailey TH. The surgical management of anorectal diseases in AIDS and pre-AIDS patients. Dis Colon Rectum 1986;29(11):719-723

39 Hosking SW, Smart HL, Johnson AG, Triger DR. Anorectal varices, haemorrhoids, and portal hypertension. Lancet 1989;1(8634): 349-352

40 Johansen K, Bardin J, Orloff MJ. Massive bleeding from hemorrhoidal varices in portal hypertension. JAMA 1980;244(18): 2084-2085 